\title{
The Impact of Fixed and Mobile Telephones on Economic Growth in Algeria during the Period from 1963 to 2015
}

\author{
Leila Khaouani
}

Department of Economics, Tlemcen University, Algeria

Copyright $\mathrm{C} 2019$ by authors, all rights reserved. Authors agree that this article remains permanently open access under the terms of the Creative Commons Attribution License 4.0 International License

\begin{abstract}
Communication is considered as an inevitable consequence of any development policy, whether economic or social, and among the various types of communication, telecommunication representing one of the irreplaceable infrastructure for any society. The demand on these services is increasing, from a simple telephone line to the establishment an information transmission network that dominates the different substrates of conversion, cable, fiber optic, satellite, etc. The telecommunications sector at Algeria has been monopolized by the state and has suffered greatly in response to the growing demand for telephone lines. But things have changed thanks to the new law of the sector, which opened the doors to private investors after thirty eight years; the State has licensed the private sector, and led to increased supply in this area. This article aims to study the causal relationship between GDP and telecommunications across the Algerian fixed and mobile telephones from 1963 to 2015. The empirical analysis moves by steps to test chronological series characteristics by using the Phillips-perron (PP) tests, the Johansen cointegration test, and the Vector Error Correction Model short-term (VECM), ending with the Granger causality test. The results showed that the coefficient is statistically significant for the VECM test, and the Granger causality test that has showed a unidirectional causal relationship between variables.
\end{abstract}

Keywords GDP, Fixed Telephone, Mobile Telephone, Cointegration, VECM, Granger Causality

\section{Introduction}

The telecommunications market in most industrialized countries and many developing countries was liberalized in the late 1990s to improve service accessibility and affordability for both businesses and households. Among its countries Algeria, this manages its telecommunications sector as public property in accordance with Article 17 of its constitution.

The resulting inadequate institutional framework led to numerous inefficiencies as expressed by a growing waiting list, distorted tariffs, poor service quality, and limited variety of services offered to consumers. Algeria lagged behind neighboring countries despite a substantial amount of public investment in the sector during the 1970s and part of the 1980s. In 1999, a new government appointed in the aftermath of President Bouteflika's election decided to change that situation and launched a comprehensive sector reform (Paul Noumba, 2006).

The objectives of the government were:

- To adapt and modernize the sector institutional framework to meet the national communication needs for the twenty first-century;

- To allow increased private sector participation through the implementation of sound market liberalization policies;

- To preserve employment losses during the reform implementation. The implementation of sound market liberalization policies was considered to be the driving factor of the sector restructuring effort (Paul Noumba, 2006).

We conclude from the above that the telecommunications sector in Algeria is monopolized by the state and really suffered in order to respond to the growing demand of telephone lines. But things have changed thanks to the new law of the telecommunications sector No. 2000-03 of 05 August 2000 (Official Gazette,2000), which opened the doors to private investors after thirty eight years, the State has licensed the private sector, which has led to increase supply in this domain.

The opening of the sector was given to three public and private operators, Algeria Telecom, Orascom Telecom-Djezzy and wataniya Telecom -Nedjma- Oredoo, 
gave the opportunity to the sector to rise telephone density during the last years, a rise in fixed telephone use from $5.80 \%$ in 2000 to $8.26 \%$ in 2016 , the number of users of this web increased moving from 1.880 million Subscribers in 2000 to 3.404 million subscribers in 2016. The number of fixed network subscribers remains relatively stagnant since the opening of the mobile phone market. The latter one responds better to the needs of the market due to its numerous advantages (mobility, SMS, value-added services, mobile Internet). (Postal and Telecommunications Regulatory Authority of Algeria, 2014)

In the other hand, the mobile phone had seen an expanding moving from $0.28 \%$ in 2000 to $113.35 \%$ in 2016 , this is due to the pre-card payment system favored by the Subscriber to its low consumption and ease of mobility, for that reason, each operator suggests the most attractive and innovative offers than the other competitive one's such as second pricing system and periodic reductions. According to Postal and Communication Control Agency, the number of subscribers in the Algerian mobile network reached to 47.041 million in 2016 in comparison to 86.000 in 2000 .

The number of subscribers to fixed and mobile networks reached 50.446 million subscribers in 2016, against 46.659 million subscribers in 2015, an increase of 3.787 million subscribers. This is can be explained by the expansion of the $3 \mathrm{G}$ subscribers and the launch of $4 \mathrm{G}$ services. Fixed and mobile tele-density stands at $121.56 \%$ in 2016, compared with $115.49 \%$ in 2015 . (ARPT, the financial years 2014-2015)

The problematic of this paper is to study the major following question: Does the fixed and mobile telephone contribute to the Algerian economic growth?

This question allows us to show the importance of telephone for the economic growth prospective. A matter of establishing a relation between the gross domestic product GDP, the fixed telephone, and mobile telephone in order to show the following points:

- The measurement of telecommunications growth in terms of the economic growth;

- To test the cointegration between the fixed, and mobile telephones, and the gross domestic product;

- To test the causal relationship between the variables.

To achieve this goal, the paper proceeds as follows: the introduction, section two provides literature review, section three presents the methodology, section four discusses the empirical results and section five concludes.

\section{Literature Review}

The economic literature contains studies on telecommunications in relation to economic growth. A review of this work helps to refocus the issue and to make a thorough analysis. The correlation between the development of the telecommunications network and growth has been the subject of several attempts at measurement, such as those which have sought, by econometric methods, to link the telephone density to a development indicator such as the Gross Domestic Product (GDP).

\subsection{The Classic Literature}

Professor JIPP's study (1963) compared the level of telephone density to per capita income. He shows that the rich countries have the highest telephone density in comparison to those in poorest countries. He clarified this idea in a form of a curve called the JIPP's curve. The curve shows the development of the telephone density and their consistency with the needs of the country and its degree of well-being (Goodman, James, 2003). We name some experiments under the program of OCDE by using the JIPP's curve under these tests, and the transformation known by southern Asian countries (Bangladesh, Sri Lanka, India and Pakistan), and Africa (Ghana, Kenya, Nigeria and Uganda) has been checked. The Jipp's curve has been used for the period of 2000-2006, and from this curve, we conclude the following results: (M. Sam Paltridge, 2008)

- In Southern Asian countries, registered a powerful growth in Sri Lanka and Pakistan in line with the liberalization of its sector at an early date, not the case for India and Bangladesh, they are accelerating their growth to reach the other countries.

- For the four African counties, which had been taken as a model, they have significantly surpassed average growth rates in comparison to their counterparts. We conclude from the study that in the old environment the investment was in line with the economic growth, and for the new environment, it is obviously that the development of telecommunication may well exceed the overall economic development.

Hardy, Andrew P. (1980) investigated the impact of telephones per capita on economic growth, a growing number of studies have attempted to identify telecommunications as an essential component of the economic infrastructure, fostering productivity and economic growth. Hardy shows, by analyzing the correlation of data series with staggered delays, that a change in the telephone density causes a variation of GNP of the per capita, and reciprocally that a modification of GNP of the per capita induced a variation of the telephone density. This finding leads this author to defend the thesis of the existence of a double causality between the number of telephone lines and the level of economic development measured by GDP per capita. Hardy also notes that this ripple effect is inversely proportional to the level of telecommunications equipment in the considered countries. It is joined in its conclusions in 1988 by a quantitative study of the ITU showing that the marginal contribution of 
a telephone line to GDP is even stronger when the country is a poorer one. The importance of this marginal contribution in developing countries is probably due to the fact that the telephone networks mainly serve high-traffic professional subscribers.

\subsection{The Representative Literature}

In the literature, that has been similar research that has investigated the relationship between investment in telecommunications and economic growth have been examined in various ways. Several studies have used time series analyzes such as Granger causality tests and modified Sims tests, and focused on the strength and direction of the causal relationship between investment in telecommunications infrastructure and economic growth.

For instance, Cronin et al. (1993) and Wolde-Rufael (2007) confirmed a two-way causal relationship in the US between telecommunications infrastructure investment and economic growth. In a similar study, however, Beil et al. (2005) conducted Granger-Sims causality tests for a time series of 50 years in the US, and suggested a one-way causality from economic growth to telecommunications investment. Dutta (2001) applied Granger causality tests for a cross section of 30 developing and industrialized countries in three different years, and found a bi-directional causality for both developing and industrialized countries. Perkins et al. (2005) also identified a bi-directional causality in South Africa using a PSS F-test (Pesaran et al., 2001).

Lee Sang, Levendis John, and Gutierrez Luis (2011), they examine the effect of mobile cellular phones on economic growth in sub-Saharan Africa where a marked asymmetry is present between land line penetration and mobile telecommunications expansion. This study extends previous research along two important dimensions. First, they allow us to study the relationship between economic growth and telecommunications using a special linear estimator, the Generalized Method of Moments (GMG). Second, they explicitly model for varying degrees of substitutability between mobile cellular and land line telephony, so that greater expansion of mobile telecommunications can have a different impact whenever the level of land line penetration differs.

\subsection{The Recent Research Literature}

Kawaljeet Kaur, Neena Malhotra (2014) their paper attempts to investigate the causal relationship between telecommunication development and GDP as well as various sectoral components of GDP in India. The overall results of causality indicate a long run relationship between telecommunications and economic growth at aggregate level as well as at sectoral level. However, the direction of causality is different from case to case. In case of GDP per capita, direction of causality is from tele-density to GDP which reveals that telecommunications contribute to overall economic growth. In addition to it, in case of industry, there is no causality. In the case of manufacturing, there is bi-directional causality. Further the case of services indicates the direction of causality from services to tele-density all the services using telephone facilities in one-way or other are contributing to the growth of telecommunications. Next is the case of FIRB services, the results indicate causality from FIRB services to tele-density which reveals that finance, Insurance and business services contribute to the growth of tele-density. Further, the case of TTHC services shows causality from TTHC services to telecommunication indicating cause and effect relationship between the two sectors. Last is the Social, personal and community (SPC) services whereby direction of causality is from tele-density to SPC services. The results of the Chow test indicate that there is structural break in the economic data of the country which has significant implications. The study found structural break in data in 1995 weakly and strongly after 2005 which indicates strong impact of telecommunications on development of various sectors of the economy.

Rudra P. Pradhan, Mak B. Arvin, Sahar Bahmani, Neville R. Norman (2014) Their paper examines the nexus between the development of telecommunications infrastructure (DTI), economic growth, and four key indicators of the operations of advanced economies. It employs a panel vector auto-regressive model to detect causality and examine long-run relationships between variables in the G-20 countries for the period 2001-2012. The results provide evidence that the development of telecommunications infrastructure generally causes economic growth and that the causation may be bidirectional. Furthermore, this paper demonstrates that economic growth and the development of telecommunications infrastructure may also be causally linked to other macroeconomic variables. An important result here concerns the relationship between DTI and FDI. Finally, the results confirm the presence of a long-run relationship between all variables considered, irrespective of whether the countries are developed or developing.

Mohina Saxena, S. Bhattacharyya (2017) their paper looks into the interlinkage between advancement in Indian telecommunications infrastructure and associated enhanced economic during 1981-2014. They identify other economic determinants such as gross domestic investment, total trade volume and real effective exchange rate that might have affected the overall economic activities in India. They perform a multivariate VAR analysis. While there has been absence of long run relationship, short run unidirectional causality remained valid. The absence of long run relationship could arise due to heterogeneity of telecommunications penetration between rural and urban areas. Such a significant "digital divide" contributes to impede the development of telecommunications 
infrastructure in rural areas and hence, constraints the overall effect of telecommunications infrastructure on economic growth.

\section{Econometric Study Procedures}

In order to better explain the contribution of fixed and mobile telephony to economic growth, time series were used to estimate the model adopted, using the co-integration model and causality model.

\subsection{Model of Cointegration: The Johansen Approach (1998)}

\subsubsection{Definition of Cointegration}

Cointegration is a statistical property of a collection of time series variables. First, all of the series must be integrated of order $\mathrm{d}$. Next, if a linear combination of this collection is integrated of order less than $d$, then the collection is said to be cointegrated.

\subsubsection{The Cointegrating Conditions}

Two series $\mathrm{Xt}$ and $\mathrm{Yt}$ are co integrated if the two following conditions are true:

1. They are integrated order $\mathrm{d}$;

2. The linear combination of these 2 series allows reducing to a series of lower order of integration.

In order to check whether the regression performed on non-stationary variables will not be spurious, a cointegration test must first be realized. (Bourbonnais R., 2015)

\subsubsection{Synthesis of the Procedure of the Cointegration and} VECM Estimation

Step 1: Stationary test on the series to determine whether there is a possibility of cointegration or not. The tests of Dickey-Fuller, Dickey-Fuller Augmented and Phillips-Perron make it possible to account for the stationary or not of a series. The Augmented Dickey-Fuller test has been proposed to improve the Dickey-Fuller test by taking into account the fact that the errors are not white noises but can be correlated. The Phillips-Perron test integrates the heteroscedasticity of the errors.

Step 2: If the stationary test shows that the series are integrated in the same order, there is a risk of cointegration. We can consider estimating a VECM model. To do this, we first determine the number of p-model VAR (p) delays using the information criteria (Akaike and Schwarz).

Step 3: Implementation of the Johansen test to know the number of cointegration relationships.

To perform the trace test, it is necessary to first specify the specifications to remember:
- Absence or presence of constant in the VECM model

- Absence or presence of constant and trend in cointegration relationships.

Step 4: Identification of cointegration relationships, that is, long-term relationships between variables.

Three cases can occur:

- $\operatorname{Rg}(\Pi)=0$ so $\mathrm{r}=0$ : there is no cointegration relation. We cannot estimate a VECM model. On the other hand, it is possible to estimate a VAR model on $\triangle \mathrm{Xt}$.

- $\quad \operatorname{Rg}(\Pi)=\mathrm{r}$ : there are $\mathrm{r}$ cointegration relationships. A VECM model can then be estimated.

- $\quad \operatorname{Rg}(\Pi)=\mathrm{N}$ : there is no cointegration relationship. A VAR model can be estimated directly on Xt.

Step 5: Estimation by the maximum likelihood method of the VECM model and validation of the usual tests: significance of the coefficients and verification that the residues are white noises (Ljung-Box test).

The Ljung-Box test is based on the analysis of the Q statistic, which is defined by:

- $\quad$ The Q statistic also asymptotically follows the law of $\chi^{2}$ at $h$ degrees of freedom;

- This statistic is often preferred over Box-Pierce because of these higher asymptotic properties.

$$
Q=n(n+2) \sum_{k=1}^{h} \frac{\hat{\rho}_{k}^{2}}{n-k}
$$

\subsection{Causality Test in the Sense of Granger}

Let the model VAR (p) for which the variables y1t and $\mathrm{y} 2 \mathrm{t}$ are stationary (Hélène Hamisultane):

$\mathrm{y}_{1 \mathrm{t}}=\gamma_{1}+\alpha_{11} \mathrm{y}_{1 \mathrm{t}-1}+\alpha_{12} \mathrm{y}_{1 \mathrm{t}-2}+\ldots+\alpha_{1 \mathrm{p}} \mathrm{y}_{1 \mathrm{t}-\mathrm{p}}+$ ${ }_{1} \beta_{11} \mathrm{y}_{2 \mathrm{t}-1}+\beta_{12} \mathrm{y}_{2 \mathrm{t}-2}+\ldots+\beta_{1 \mathrm{p}} \mathrm{y}_{2 \mathrm{t}-\mathrm{p}}+\mathrm{v}_{1 \mathrm{t}}$

$\mathrm{y}_{2 \mathrm{t}}=\gamma_{2}+\alpha_{21} \mathrm{y}_{1 \mathrm{t}-1}+\alpha_{22} \mathrm{y}_{1 \mathrm{t}-2}+\ldots+\alpha_{2 \mathrm{p}} \mathrm{y}_{1 \mathrm{t}-\mathrm{p}}+\beta_{21} \mathrm{y}_{2 \mathrm{t}-1}$

$+\beta_{22} \mathrm{y}_{2 \mathrm{t}-2}+\ldots+\beta_{2 \mathrm{p}} \mathrm{y}_{2 \mathrm{t}-\mathrm{p}}+\mathrm{v}_{2 \mathrm{t}}$

The test consists in asking these two hypotheses:

- $\quad y 2 t$ does not cause y1t if the following hypothesis H0 is accepted:

$$
\beta 11=\beta 12=\beta 13=\ldots=\beta 1 p=0
$$

- $\quad y 1 t$ does not cause $y 2 t$ if the following hypothesis H0 is accepted:

$$
\alpha 21=\alpha 22=\alpha 23=\ldots=\alpha 2 p=0
$$

\section{Analysis of Data}

This paper explores the relation between gross domestic product and fixed and mobile telephones using data from Algeria for the period 1963-2015. 


\subsection{Presentation of Data}

\subsubsection{Gross Domestic Product (\$US Constant 2005)}

Gross domestic product (GDP) is the most important indicator for assessing a country's production of goods and services in a year. It illustrates the importance of a country's economic activity.

When it is formulated in constant dollars, as is the case here, comparisons can be made more appropriately over the years since we then take into account inflation or deflation.

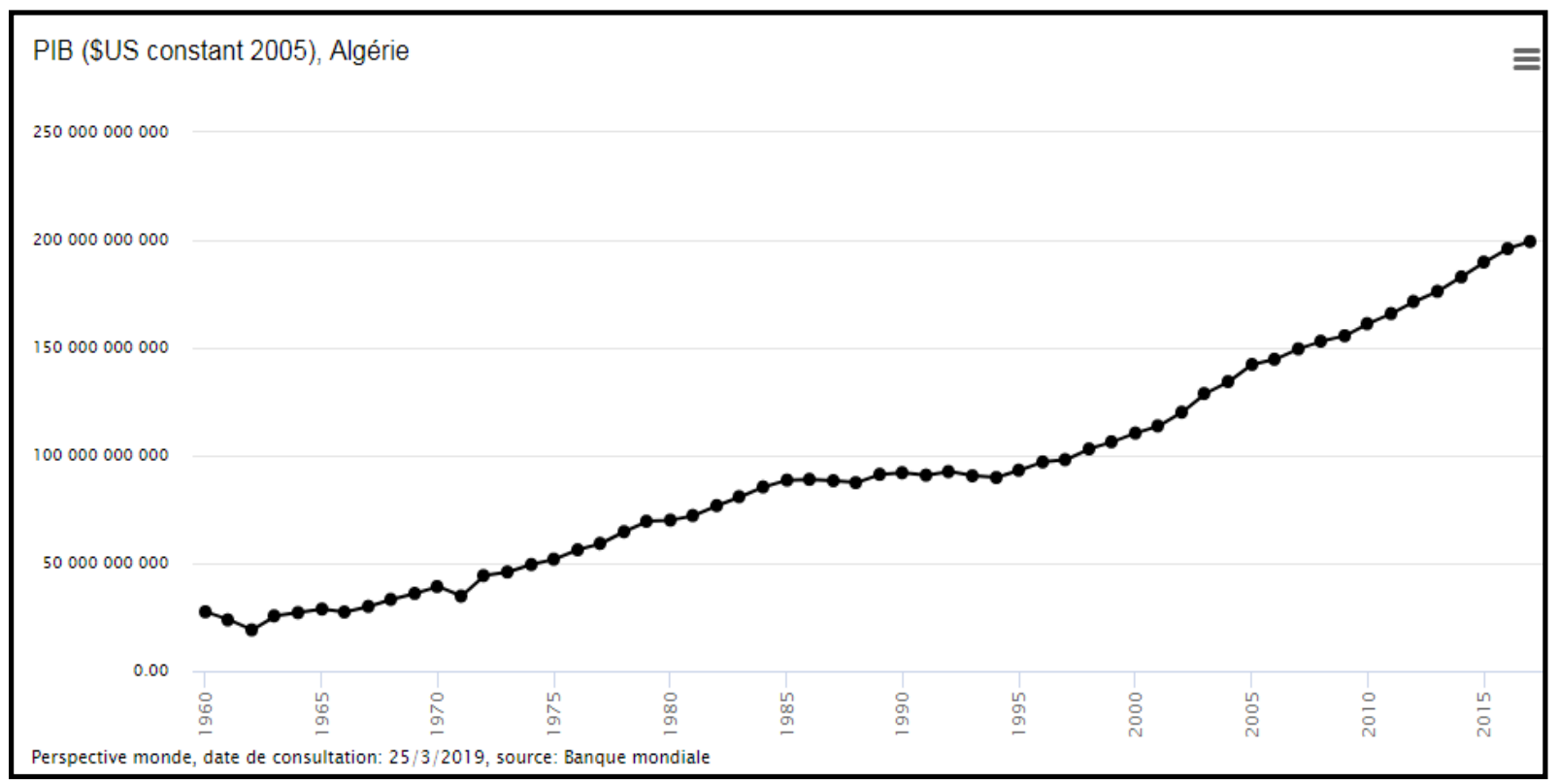

Source: world Bank

Figure 1. Gross Domestic Product (\$USconstant2005)

In the diagram above, we see that the GDP increases for the period 1963-2015, it represents the results of 53 years. the value of 25568113636 is recorded during the year 1963 and the value 89772000000 in 2015.

\subsubsection{Fixed Telephone}

Fixed telephone, or residential telephone, corresponds to telephone systems whose subscriber terminal line is located at a fixed location.

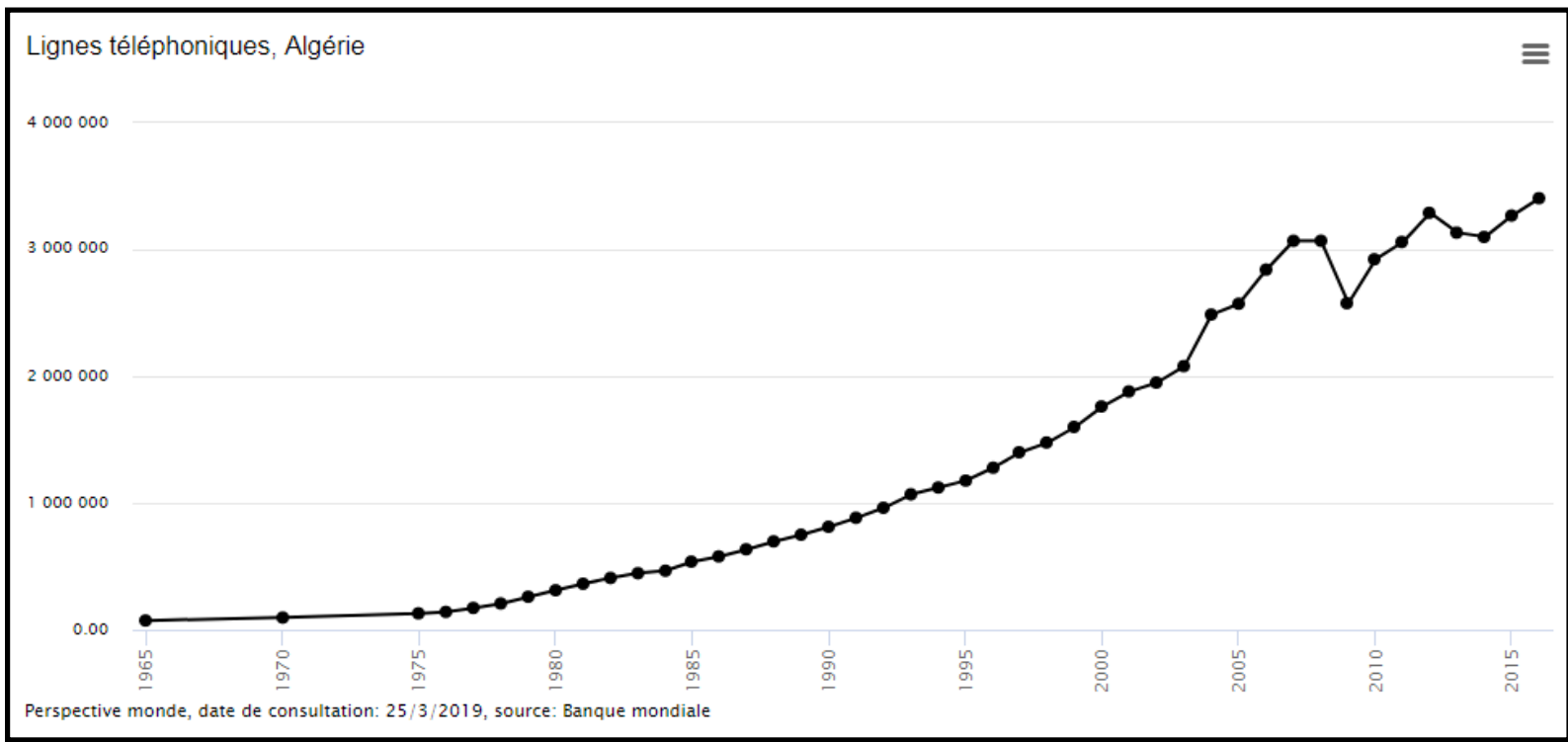

Source: world Bank

Figure 2. Fixed Telephone 
According to the figure above, the number of subscribers to the fixed network has increased from 57529 lines for the year 1963 to 1880200 lines at the end of 2001, and the telephone density was estimated at 6 lines per hundred inhabitants.

The number of subscribers to the fixed network at the end of 2015 is 3267592 subscribers with the penetration rate is $8.09 \%$, consequently the number of subscribers to the fixed network has remained relatively stagnant since the opening of mobile telephony market.

\subsubsection{Mobile Telephone}

The mobile phone, also called cellular phone, has revolutionized our daily lives by allowing us to communicate wirelessly wherever there is a mobile phone network.

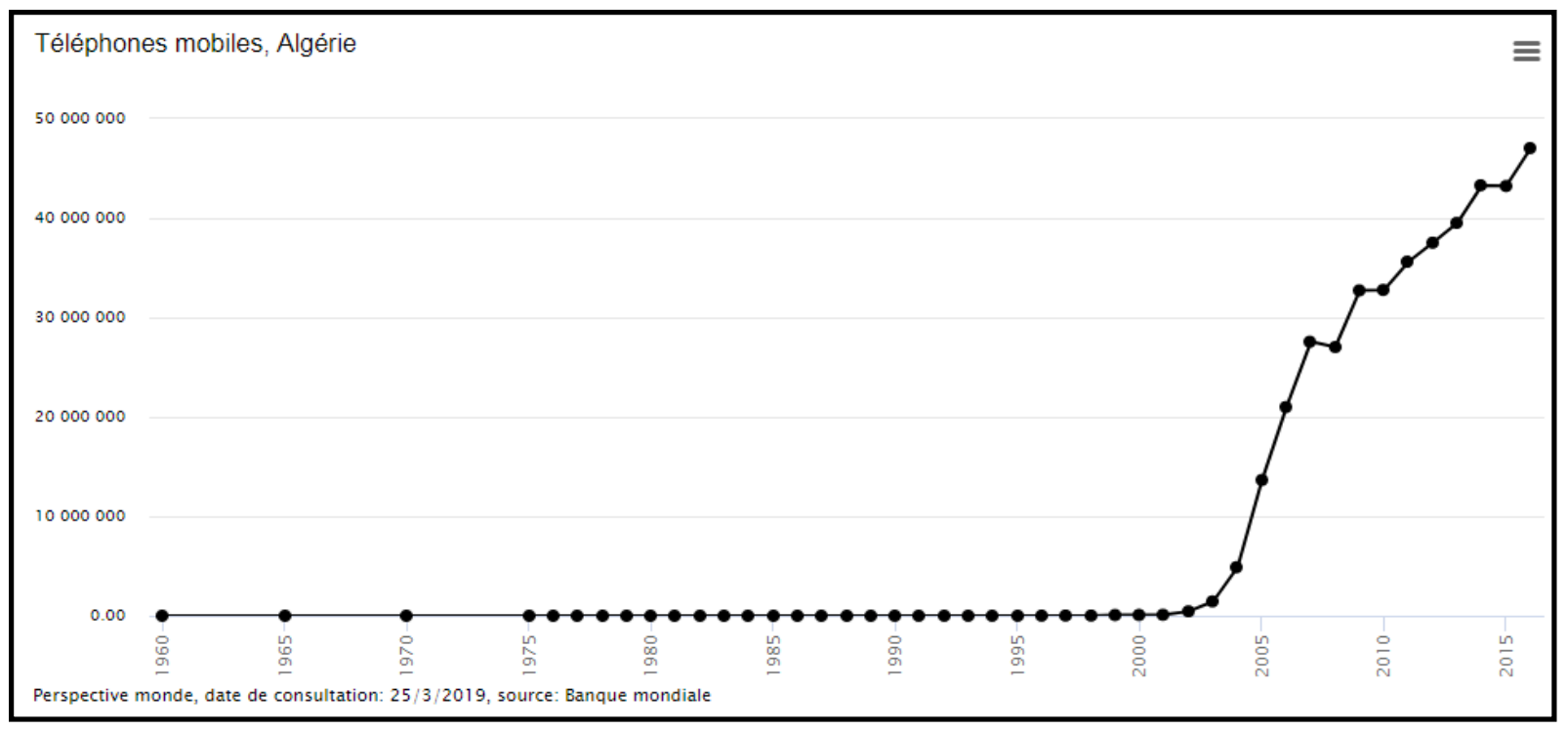

Source: world Bank

Figure 3. Mobile Telephone

The new law $\mathrm{n}^{\circ}$ 03-2000 dated August 5, 2000 of the telecommunications sector, which opened the doors to private investors Orascom Telecom-Djezzy (private) and wataniya Telecom - Nedjma (private), plus the public operator Algeria Telecom.

According to the figure above, The mobile phone saw an expansion from $0.28 \%$ in 2000 to $107.00 \%$ in 2015 , and the number of subscribers has increased from 86000 lines to 43227643 lines at the end of 2015, due to the pre-card payment system that was preferred by the subscriber.

\subsection{Description of the Data}

This paper is designed to examine whether fixed telephone (Fixedtel), and mobile telephone (Mobiletel) affect Gross domestic product (GDP) of Algeria.

We report that the time period for which we have received data is from 1963 to 2015 . The source of the data is world bank, and the data refer 53 years. Therefore, our model is as follows:

Yit $=\mathrm{bo}+\mathrm{b} 1 \mathrm{X} 1 \mathrm{t}+\mathrm{b} 2 \mathrm{X} 2 \mathrm{t}+\mathrm{Uit}$

Yt: Gross domestic product for year $\mathrm{t}(\mathrm{GDP})$ where the time series have been expressed at constant prices.

$\mathrm{X} 1 \mathrm{t}$ : the number of fixed line subscribers for year $\mathrm{t}$ (Fixedtel),

$\mathrm{X} 2 \mathrm{t}$ : the number of mobile line subscribers for year $\mathrm{t}$ (Mobiletel).

Uit: random this paper is designed to examine whether fixed telephone (Fixedtel), and mobile telephone (Mobiletel) affect Gross domestic product variable that takes into account random cross-sectional effects, that is, the factors that affect the dependent variable.

The result from the estimate of the regression is presented in the following table: 
Table 1. Estimation Equation

\begin{tabular}{|lrlll|}
\hline \multicolumn{1}{c}{ Variable } & Coefficient & Std. Error & t-Statistic & Prob. \\
\hline \multicolumn{1}{c}{ C } & $-1.72 \mathrm{E}+15$ & $5.12 \mathrm{E}+14$ & -3.369621 & 0.0015 \\
FIXEDTEL & $5.27 \mathrm{E}+09$ & $5.22 \mathrm{E}+08$ & 10.08098 & 0.0000 \\
MOBILETEL & 71391946 & 42525830 & 1.678790 & 0.0994 \\
\hline \hline R-squared & 0.898430 & Mean dependent var & $4.92 \mathrm{E}+15$ \\
Adjusted R-squared & 0.894367 & S.D. dependent var & $7.10 \mathrm{E}+15$ \\
S.E. ofregression & $2.31 \mathrm{E}+15$ & Akaike info criterion & 73.64308 \\
Sum squaredresid & $2.66 \mathrm{E}+32$ & Schwarzcriterion & 73.75461 \\
Log likelihood & -1948.542 & Hannan-Quinn criter. & 73.68597 \\
F-statistic & 221.1362 & Durbin-Watsonstat & 0.447119 \\
Prob(F-statistic) & 0.000000 & & \\
\hline
\end{tabular}

Source: constructed from the study data Program Eviews 9

In the present study, The result is estimated Linear Model using the Ordinary Least Squares (OLS), according to this method, we look for a line that minimizes the sum of squares of residues, through the Eviews econometric program 9.

According to the table above we obtained the following estimated equation:

$\mathrm{GDP}=\mathrm{C}(1)+\mathrm{C}(2) *$ FIXEDTEL $+\mathrm{C}(3) *$ MOBILETEL

GDP $=-1.72372259216 \mathrm{e}+15+5265835832.8 *$ FIXEDTEL $+71391946.0346 *$ MOBILETEL

- $t$-statistic is significant when the probability is less than 0.05 for all variables:

Constant (t-statistic of $\mathrm{C}=-3.369621 ; \quad \mathrm{Prob}=0.0015<0.05) ; \quad$ Fixedtel $\quad$ (t-statistic of Fixedtel=10.08098; Prob=0.0000<0.05); Mobiletel (t-statistic of Mobiletel =1.678790; Prob $=0.0994>0.05$ )

- The R2 (R-squared) determinant is 0.898430 , which implies that the model interprets a very good percentage, about $89.84 \%$ of the variability of our data.

- the Fisher test ${ }^{1}(\mathrm{~F}$-statistic $=221.1362$ and Prob $=0.0000<0.05)$, the test $\mathrm{F}$ is significant of all the coefficients of a model.

We conclude that all the parameters are statistically significant, and the specified model explains about $89.84 \%$ of product variations gross domestic product in Algeria.

Table 2. Correlation of the Dependent and the in Dependent Variables: Correlation Matrix

\begin{tabular}{|c|c|c|c|}
\hline & GDP & FIXEDTEL & MOBILETEL \\
\hline GDP & 1 & 0.944838 & 0.831857 \\
\hline FIXEDTEL & 0.944838 & 1 & 0.836554 \\
\hline MOBILETEL & 0.831857 & 0.836554 & 1 \\
\hline
\end{tabular}

Source:constructedfromthestudydataProgramEviews9

Correlation measures both the strength and direction of the linear relationship between two variables. According to the table above result of correlation matrix is as follows:

- $\quad \mathrm{r}=0.944838$ correlation between GDP and Fixedtel

- $\mathrm{r}=0.831857$ correlation between GDP and Mobiletel

- $\mathrm{r}=0.836554$ correlation between Mobiletel and Fixedtel

There is a positive and strong relationship between the variables. The points are close to the line, which indicates that there is a strong relationship between the variables. The relation is positive because the variables increase simultaneously.

We conclude that there is a significant linear correlation between the pair.

1 The Fisher test makes it possible to test the significance of all the coefficients of a model. The decision rule is: If $f>f *(p, q)$ where $f *(p, q)$ is the value given by the Fisher table for given $\mathrm{p}$ and $\mathrm{q}$ and for a fixed risk $\Rightarrow$ We accept H1: there is at least one non-zero coefficient. It is less accurate than the Student test. 


\section{Results and Discussion}

\subsection{Unit Root Test}

Phase one is to test whether the variables contain a unit root to confirm the stationarity of each variable. This is done by using the Philips-Perron (PP) test. The results are displayed in Table 3.

Table 3. Results of Phillips-Perron Test

\begin{tabular}{|c|c|c|c|c|c|c|}
\hline \multirow[t]{2}{*}{ variables } & \multicolumn{2}{|c|}{ the gross domestic product(GDP)* } & \multicolumn{2}{|c|}{ Fixed telephone* } & \multicolumn{2}{|c|}{ Mobile telephone* } \\
\hline & level & $1_{\mathrm{ST}}$ difference & level & $1_{\mathrm{ST}}$ difference & level & $1_{\mathrm{ST}}$ difference \\
\hline Intercept & $\begin{array}{c}0.522356 \\
(0.9860)\end{array}$ & $\begin{array}{c}-6.946036 \\
(\mathbf{0 . 0 0 0 0 )}\end{array}$ & $\begin{array}{l}1.514945 \\
(0.9992) \\
\end{array}$ & $\begin{array}{l}-6.913781 \\
(\mathbf{0 . 0 0 0 0 )}\end{array}$ & $\begin{array}{l}1.655737 \\
(0.9995) \\
\end{array}$ & $\begin{array}{c}-3464963 \\
(\mathbf{0 . 0 1 3 1}) \\
\end{array}$ \\
\hline Trend and intercept & $\begin{array}{c}-1.460571 \\
(0.8304) \\
\end{array}$ & $\begin{array}{c}-7.221498 \\
(\mathbf{0 . 0 0 0 0 )} \\
\end{array}$ & $\begin{array}{c}-1.766622 \\
(0.7065)\end{array}$ & $\begin{array}{c}-7.891480 \\
(\mathbf{0 . 0 0 0 0 )}\end{array}$ & $\begin{array}{c}-0.023639 \\
(0.9949)\end{array}$ & $\begin{array}{c}-4.173556 \\
(\mathbf{0 . 0 0 9 3 )}\end{array}$ \\
\hline None & $\begin{array}{l}1.444415 \\
(0.9614)\end{array}$ & $\begin{array}{c}-6.596690 \\
\mathbf{( 0 . 0 0 0 0 )} \\
\end{array}$ & $\begin{array}{r}3.452265 \\
(0.9998) \\
\end{array}$ & $\begin{array}{c}-5.637227 \\
\mathbf{( 0 . 0 0 0 0 )} \\
\end{array}$ & $\begin{array}{r}2.309469 \\
(0.9944) \\
\end{array}$ & $\begin{array}{c}-3.115934 \\
\mathbf{( 0 . 0 0 2 4 )} \\
\end{array}$ \\
\hline Order of integration & \multicolumn{2}{|c|}{$\mathrm{I}(1)$} & \multicolumn{2}{|c|}{$\mathrm{I}(1)$} & \multicolumn{2}{|c|}{$\mathrm{I}(1)$} \\
\hline
\end{tabular}

*Indicates significant at $5 \%$

The value in brackets represents probability

Source: constructed from the study data Program Eviews 9

Test the order of integration of Phillips and Perron shows that the calculated values are greater than the tabulated values at the 5\% significance level, we accept the null hypothesis where the time series have a unit root. This confirms that the series considered are not integrated with the same order Table 3 of the Phillips and Peron test shows that series fixed telephone, mobile telephone and GDP are integrated in order one, this result obtained shows that the series are stationary and there is a possibility of cointegration.

\subsection{Cointegration Method}

Table 4. Johansen Test to Cointegration

\begin{tabular}{|c|c|c|c|c|c|c|c|}
\hline $\begin{array}{c}\text { Hypothesize d no } \\
\text { of ce (s) }\end{array}$ & Eigen value & Trace statistic & $\begin{array}{c}\text { Critical } \\
\text { value } 0.05\end{array}$ & Prob** & $\begin{array}{c}\text { Max-Eigen } \\
\text { statistic }\end{array}$ & $\begin{array}{c}\text { Critical value } \\
0.05\end{array}$ & Prob** \\
\hline None*(r=0) & 0.431236 & $\mathbf{4 8 . 9 3 3 4 8}$ & 42.91525 & $\mathbf{0 . 0 1 1 2}$ & $\mathbf{2 8 . 7 7 8 8 0}$ & 25.82321 & $\mathbf{0 . 0 1 9 8}$ \\
\hline ATmost1 & 0.237281 & 20.15468 & 25.87211 & 0.2182 & 13.81412 & 19.38704 & 0.2668 \\
\hline ATmost2 & 0.116907 & 6.340566 & 12.51798 & 0.4183 & 6.340566 & 12.51798 & 0.4183 \\
\hline
\end{tabular}

Trace test indicates 1 co integrating eqn(s) at the 0.05 level

Max-eigen value test indicates 1 co integrating eqn(s) at the 0.05 level

* denotes rejection of the hypothesis at the 0.05 level

**MacKinnon-Haug-Michelis (1999) p-values

Source: constructed from the study data Program Eviews 9

The purpose of the cointegration method is to find the real relation between the studied variables, although the original series are not stationary, this method has two phases:

Step 1: Implementation of the Johansen test to know the number of cointegration relationships.

The results of the impact test ( $\lambda_{\text {trace }}$ ) of Table 4 indicate rejection of the null hypothesis $(r=0)$ and acceptance of the alternative hypothesis, so that the calculated value of $\left(\lambda_{\text {trace }}\right)(48.93348)$ is greater than (42.91525) at a significant level of 5\%. The Max-Eigen statistical test gave the same results as the calculated value (28.77880) is greater than (25.82321) at Critical value 0.05 . The Johansen test also allowed us to find a common integration vector that lies in a long-run equilibrium relationship between the variables, uniform relationship between GDP, fixed telephone and mobile telephone integration variables through a long-term relationship leads us to find a VECM model.

Step 2: Vector Error Correction Model 
Table 5. Vector Error Correction Model

\begin{tabular}{|c|c|c|c|}
\hline Cointegrating Eq: & CointEq 1 & & \\
\hline $\operatorname{GDP}_{(-1)}$ & 1.000000 & & \\
\hline FIXEDTEL $(-1)$ & $\begin{array}{l}4.53 E+09 \\
(2.7 E+09) \\
{[1.96364]}\end{array}$ & & \\
\hline MOEILETEL(-1) & $\begin{array}{r}-7.64 E+08 \\
(2.1 E+08) \\
{[-3.67150]}\end{array}$ & & \\
\hline$c$ & $-5 \cdot 19 E+15$ & & \\
\hline Error Correction: & $D(G D P)$ & $D(F \mid \times E D T E L)$ & D(MOBILETEL) \\
\hline CointEq 1 & $\begin{array}{c}0.029955 \\
(0.04060) \\
{[0.73780]}\end{array}$ & $\begin{array}{r}6.25 E-12 \\
(3.0 E-12) \\
{[2.05868]}\end{array}$ & $\begin{array}{r}-9.23 E-11 \\
(4.2 E-11) \\
{[2.21129]}\end{array}$ \\
\hline$D(G D P(-1))$ & $\begin{array}{r}-0.045067 \\
(0.15788) \\
{[-0.28545]}\end{array}$ & $\begin{array}{r}-7.59 E-14 \\
(1.2 E-11) \\
{[-0.00643]}\end{array}$ & $\begin{array}{r}-1.28 E-10 \\
(1.6 E-10) \\
{[-0.78688]}\end{array}$ \\
\hline$D(F \mid X E D T E L(-1))$ & $\begin{array}{l}6.01 E+08 \\
(1.9 E+09) \\
{[0.309411}\end{array}$ & $\begin{array}{r}-0.164860 \\
(0.14522) \\
{[-1.13524]}\end{array}$ & $\begin{array}{l}3.923448 \\
(1.99661) \\
{[1.96506]}\end{array}$ \\
\hline D(MOEILETEL $(-1))$ & $\begin{array}{r}-928244.3 \\
(1.1 E+08) \\
{[-0.00878]}\end{array}$ & $\begin{array}{r}0.020223 \\
(0.00790) \\
{[2.55906]}\end{array}$ & $\begin{array}{l}0.479421 \\
(0.10865) \\
{[4.41255]}\end{array}$ \\
\hline$c$ & $\begin{array}{l}3.53 E+14 \\
(2.7 E+14) \\
{[1.32059]}\end{array}$ & $\begin{array}{r}55611.76 \\
(19991.0) \\
{[2.78183]}\end{array}$ & $\begin{array}{l}252491.3 \\
(274854 .) \\
{[0.91864]}\end{array}$ \\
\hline
\end{tabular}

Source: constructed from the study data Program Eviews 9

The error correction model is used when the time series are not static and co integrated, they make it possible to derive a uniform co-integration relation and to search for the real relationship between the variables.

A: The error correction model is estimated using by Eviews 9 program to obtain the estimated parameters.

The upper part of the table 5 shows:

- That the coefficients of the long-term relationship are significant (t-statistic at the 0.05 level), and the results confirm the presence of a long-run relationship between all variables.

- The coefficients of the long-term relationship are significant, given that the finding that Fixedtel, Mobiletel, and GDP are co integrated in the long-run.

The inferior part of the table 5 shows:

- The cointegration vector to construct the error correction model, this term is negative and significantly different from zero ( 0 ) for mobile phone (calculated $\mathrm{t}$-statistic $=2.21129 \mathrm{P}$-statistic tabulated $=$ $1.96^{2}$, with the number of observations is 53 ).
- The Fixedtel rate depends on the mobile rate (calculated $\mathrm{t}$-statistic $=1.96506>\mathrm{t}$-statistic tabulated $=$ $1.96, \mathrm{n}=53$ )

- The mobile rate depends on its past values and the Fixedtel rate (calculated t-statistic $=4.41255 ; 2.55906>$ $\mathrm{t}$-statistic tabulated $=1.96, \mathrm{n}=53$ ), which reflects the impact of the mobile variable on the fixed telephone variable.

Finally from the table above, partial adjustment rate coefficient took the expected negative sign, and so the estimated relationship is true, although the original series are not stationary.

B: The second stage is to examine the significance of the parameters of the model, and this is done through the statistic Q (Ljung-Box), which is in Table 6,7, and 8. 
Table 6. Correlogram of Resid 01

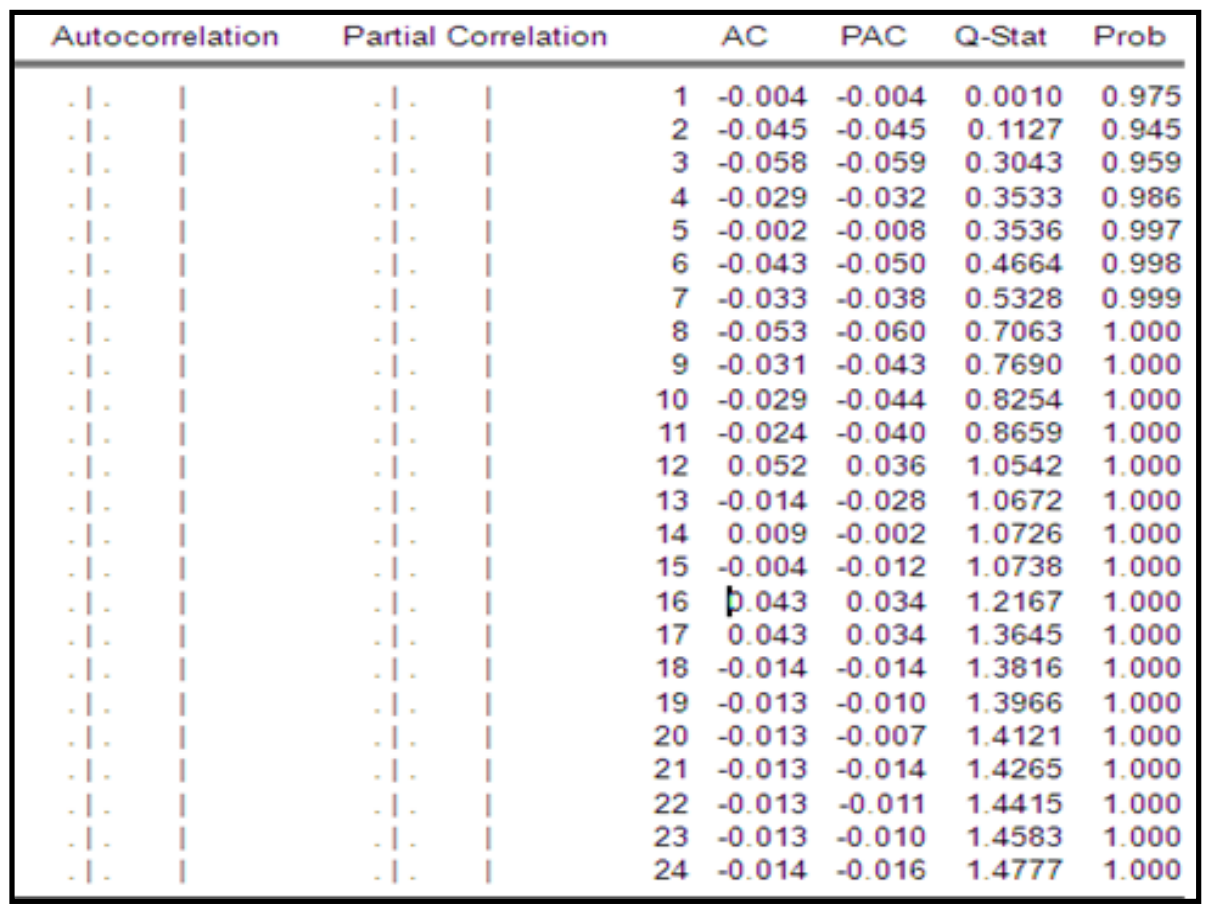

Source: constructed from the study data Program Eviews 9

The Q statistic of Ljung-Box for the delay $\mathrm{h}=24$ confirms the absence of autocorrelation. Indeed, the probability of the test for $\mathrm{h}=24$ is $1.000>0.05$, so the null hypothesis of white noise accepted.

Table 7. Correlogram of Resid 02

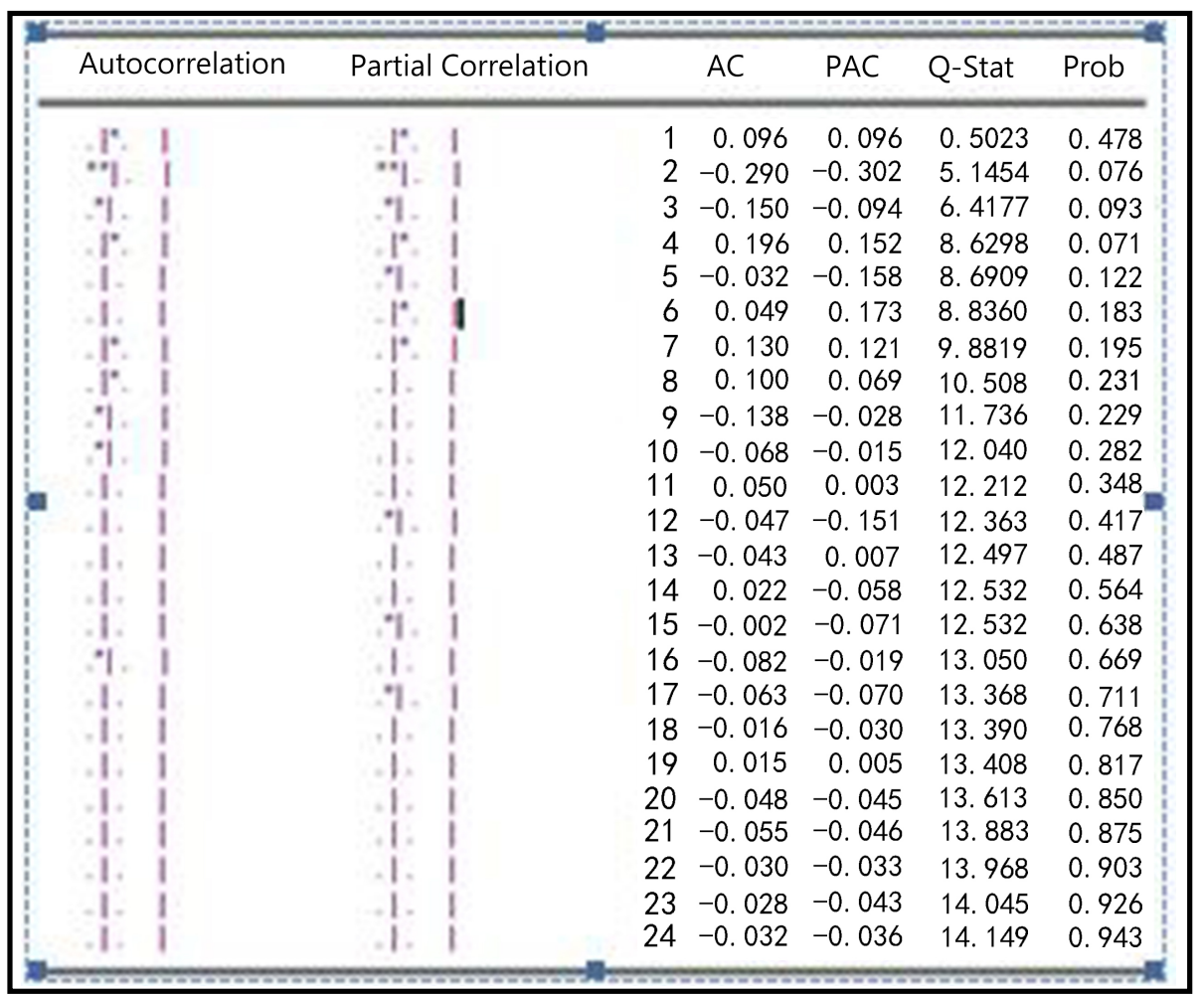

Source: constructed from the study data Program Eviews 9

The Q statistic of Ljung-Box for the delay $h=24$ confirms the absence of autocorrelation. Indeed, the probability of the test for $\mathrm{h}=24$ is $0.943>0.05$, so the null hypothesis of white noise accepted. 
Table 8. Correlogram of Rresid 03

\begin{tabular}{|c|c|c|c|c|c|c|c|}
\hline & Autocorrelation & Partial Correlation & & $A C$ & PAC & Q-Stat & Prob \\
\hline & $\therefore 1$ & $\therefore 1$ & 1 & -0.175 & -0.175 & 1.6492 & 0.199 \\
\hline & i. i & $i=i$ & 2 & 0.185 & 0.160 & 3. 5451 & 0.170 \\
\hline & 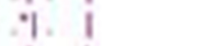 & $\therefore \quad$ i & 3 & -0.134 & -0.083 & 4. 5559 & 0.207 \\
\hline & .1. 1 & .1 .1 & 4 & 0.062 & 0.002 & 4. 7762 & 0.311 \\
\hline & 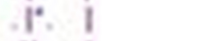 & 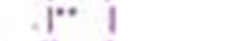 & 5 & 0.202 & 0.262 & 7. 1754 & 0.208 \\
\hline & $\therefore 1$ & $\therefore 1$ & 6 & -0.185 & -0.167 & 9. 2241 & 0.161 \\
\hline & 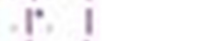 & .1 .1 & 7 & 0.121 & 0.015 & 10. 117 & 0.182 \\
\hline & i. i & 101 & 8 & 0.021 & 0.180 & 10. 145 & 0.255 \\
\hline & .1. 1 & $\therefore$ I & 9 & 0.016 & -0.083 & 10. 163 & 0.337 \\
\hline & .1. 1 & $\therefore \quad 1$ & 10 & -0.019 & -0.080 & 10. 187 & 0.424 \\
\hline ขa & $\therefore 1$ & i. i & 11 & -0.092 & 0.026 & 10. 756 & 0.464 \\
\hline & $\therefore 1$ & $\therefore 1$ & 12 & -0.072 & -0.197 & 11.115 & 0.519 \\
\hline & $\because 1$ & $\therefore 1$ & 13 & -0.076 & -0.131 & 11.528 & 0.567 \\
\hline & -1. 1 & 1. 1 & 14 & -0.048 & 0.036 & 11.695 & 0.631 \\
\hline & .1 .1 & i. i & 15 & -0.012 & -0.056 & 11.706 & 0.701 \\
\hline & 1. 1 & $\therefore 1$ & 16 & -0.047 & -0.066 & 11.877 & 0.752 \\
\hline & 1. 1 & 1. 1 & 17 & -0.039 & 0.042 & 11.997 & 0.800 \\
\hline & -1. 1 & 1. 1 & 18 & -0.029 & -0.028 & 12. 067 & 0.844 \\
\hline & 1. 1 & 1. 1 & 19 & -0.028 & -0.043 & 12. 135 & 0.880 \\
\hline & 1. 1 & 1. 1 & 20 & -0.032 & 0.028 & 12. 226 & 0.908 \\
\hline & 1. 1 & .1. 1 & 21 & -0.027 & -0.010 & 12. 294 & 0.931 \\
\hline & 1. 1 & 1. I & 22 & -0.021 & -0.056 & 12. 336 & 0.950 \\
\hline & -1. 1 & 1. 1 & 23 & -0.039 & -0.049 & 12. 484 & 0.962 \\
\hline & i. i & i. i & 24 & -0.025 & -0.051 & 12.545 & 0.973 \\
\hline
\end{tabular}

Source: constructed from the study data Program Eviews 9

The $\mathrm{Q}$ statistic of Ljung-Box for the delay $\mathrm{h}=24$ confirms the absence of autocorrelation. Indeed, the probability of the test for $h=24$ is $0.973>0.05$, so the null hypothesis of white noise accepted.

We note that the Q-stat statistic calculated in previous cases is smaller than the predicted Q-stat statistic at 24 degrees of freedom and the 0.05 threshold of the chi-square table indicating the acceptance of the null hypothesis, And that the test probability of Q-stat statistic (prob $>0.05$ ) is higher than the confidence level, which makes us accept the null hypothesis that the coefficients of the model are white noises, and we conclude that the error correction model is significant.

\subsection{Granger's Test of Causality}

We concluded from previous results that the coefficient of determination explained the independent variable by $89.84 \%$ total variation of the dependent variable, but did not imply a causal relationship, in which case we use the Granger test.

We can see through the Fisher statistic shown in Table 9 the following results:

- Fixedtel influence GDP because probability is less than $0.05(0.0108<0.05)$ So H0 rejected $)$, on the other hand GDP does not influence Granger Fixedtel because the probability is greater than 0.05 $(0.4446>0.05)$. The unidirectional causality fixe telephone from economic growth to telecommunications, indicating that telecommunications is a consequence of economic growth.

- Mobiletel does not Granger cause GDP because the probability is greater than $0.05(0.9162>0.05)$, on the other hand GDP cause Mobiletel because probability is less than $0.05(0.0001<0.05)$. The unidirectional Causality from economic growth to telecommunications (mobile telephone), indicating that telecommunications advancement is a consequence of economic growth.

- the probability of rejection in the equations is 0.0741 , 9.E-05 less than 0.05 , which confirms the causal relationship between Fixedtel and Mobiletel variables in both directions, meaning that variable 1 causes variable 2, and vice versa.

- Lastly we find the existence of unidirectional causality from fixed telephone to Gross domestic product, and Gross domestic product to mobile telephone. We also find the existence of bidirectional causality between Fixedtel and Mobiletel. 
Table 9. Granger Causality Tests

\begin{tabular}{|lccc|}
\hline $\begin{array}{l}\text { Sample: } 19632015 \\
\text { Lags: } 1\end{array}$ & Obs & F-Statistic & Prob. \\
\hline \hline Null Hypothesis: & 52 & 7.02996 & 0.0108 \\
\hline \hline FIXEDTEL does not Granger Cause GDP & & 0.59400 & 0.4446 \\
\hline GDP does not Granger Cause FIXEDTEL & \multirow{2}{*}{52} & 0.01119 & 0.9162 \\
\hline \hline MOBILETEL does not Granger Cause GDP & & 17.8220 & 0.0001 \\
GDP does not Granger Cause MOBILETEL & \multirow{2}{*}{52} & 3.32980 & 0.0741 \\
\hline \hline & & 18.2996 & 9. E-05 \\
\hline MOBILETEL dbes not Granger Cause FIXEDTEL
\end{tabular}

Source: constructed from the study data Program Eviews 9

\section{Conclusions}

The objective of this research is to analyze the impact telecommunications (fixed and mobile telephones) on economic growth in Algeria during the period from 1963 to 2015.

Our econometric results is to establish a long run relationship between variables, the short-term VECM model showed that the coefficient of the adjustment is statistically significant. This implies that the long-term balancing conditions influence the short-term dynamics.

Furthermore, the results provide evidence that the fixed and mobile telephone cause economic growth and that the causation may be unidirectional. Fixed telephone usage is less popular and has not reached the maturity level, and makes a contribution to economic growth, this variable attracts higher mobile telephone usage. In the latter case, economic growth Granger-causes mobile telephone usage.

The consolidated revenue (provisional) generated in 2016 by the four operators operating in the fixed and mobile segments amounts to 444 billion dinars, against 433 billion dinars realized in 2015, an increase of 11 billion dinars In absolute value, this represent a growth rate of 2 , $54 \%$ which is mainly due to the growth in $3 \mathrm{G}$ and $4 \mathrm{G}$ fleets (fixed and mobile). As regards the contribution of the telecommunications sector to the gross domestic product (GDP) for 2014, it is estimated at 2, $91 \%$, and for 2015 is estimated at $3,17 \%$.

The telecoms sector does not yet fully benefit the national economy, as the latter does not benefit from telecommunications. This low contribution of telecommunications to the national wealth is a testament to the road ahead to catch up and shows that the technological challenge remains whole. Also, the telecom equipment manufacturing sector is highly dependent on imported equipments and therefore, most of the domestic demand is met through imports rather than home production. This also affects competitiveness of Algerian telecom products in the international markets and contributes to decay the impact of telecommunications infrastructure on economic growth.

Finally, the traffic exchanged between the subscribers of the fixed and mobile networks recorded a marked growth from 91.528 billion minutes in 2014 to 119.468 billion minutes in 2015 , an increase of $32.52 \%$ compared to 2014 , knowing that the bulk of traffic is traded between mobile networks, or $96.78 \%$, against $3.22 \%$ for the fixed network.

\section{REFERENCES}

[1] ARPT. 2015. Operators / fleet of mobile subscribers active, the financial years 2014-2015, P35.

[2] Beil, R. Ford, G. and Jackson, J. 2005. On the relationship between telecommunications investment and economic growth in the United States, International Economic Journal, 19, PP. 3-9

[3] Bourbonnais R. 2015. Econometrics, courses and exercises corrected, DUNOD, 9th edition, Paris, P 299-301.

[4] Cronin, F., Colleran, E., Herbert, P. and Lewitzky, S. 1993, Telecommunications and economic growth: the contribution of telecommunications infrastructure investment to aggregate and sectoral productivity, Telecommunications Policy, 17, 677-90.

[5] Dominique Desbois. 2004. Info roads and Development: The Challenges of Globalization, available at: http://UFR-infop6.jussieu.Fr

[6] Dutta, A. 2001. Telecommunications and economic activity: an analysis of Granger causality, Journal of Management Information System, 17, 71-95.

[7] Goodman, James. 2003. Mobile telephones and social capital in Poland. A case study with Vodafone Group. Final Report, part of the Deliverable 12 (D12) of the project DEESD - Digital Europe: e-business and sustainable development, (retrieved 20 October 2008), p. 25.

[8] Hardy, Andrew P. 1980. The role of the telephone in economic development, Telecommunications Policy, Vol 5, No. 4 , pp. $278-286$. 
[9] Hélène Hamisultane. error-correction model and application, available at:https://www.yumpu.com/fr/document/view/16 950359/modele-a-correction-derreur-et-application-

[10] Hélène Hamisultane., Time series econometrics, P23, available at: https://halshs.archives-ouvertes.fr/cel-012611 74/document

[11] Jipp, A. 1963. Wealth of nations and telephone density. Telecommunications Journal, July 1963, pp. 199-201.

[12] Kawaljeet Kaur, Neena Malhotra. 2014. Telecommunications and economic growth in India: causality analysis, International Journal of Research in Business Management, India, Vol. 2, Issue 5, P 31, 44.

[13] Lee, Sang H, Levendis, John and Gutierrez, Luis. 2011. Telecommunications and economic growth: an empirical analysis of sub-Saharan Africa, Applied Economics, online: http://www.informaworld.com

[14] Mohina Saxena, S.Bhattacharyya.2017. A Time Series Analysis of the Nexus Between Telecommunications Infrastructure and Economic Growth in India, The Indian Journal of Economics, Issue No. 389, P 1,21.

[15] Official Gazette. 2000. No 48 dated 6 August 2000, Algeria.

[16] Paul Noumba UM. 2006. A policy note on telecommunications reform in Algeria. Review "notebooks of CREAD”, no 76, Algeria, P2.

[17] Perkins, P., Fedderke, J. and Luiz, J. 2005. An analysis of economic infrastructure investment in South Africa, South African Journal of Economics, 73, PP211-28.

[18] Pesaran, M., Shin, Y. and Smith, R. 2001. Bounds testing approaches to the analysis of level relationships, Journal of Applied Econometrics, 16, PP 289-326.

[19] Postal and Telecommunications Regulatory Authority. 2014. Press Kit 30, Algeria, p 8.

[20] Rudra P. Pradhan, Mak B. Arvin, Sahar Bahmani.2014.Telecommunications Infrastructure and Economic Growth: Comparative Policy Analysis for the G-20 Developed and Developing Countries, Journal of Comparative Policy Analysis, Vol. 16, No. 5, PP 401-423.

[21] Wolde-Rufael, Y. 2007. Another look at the relationship between telecommunications investment and economic activity in the United States, International Economic Journal, 21, PP199-205. 